\title{
Effect of temperature on the life cycle of Trilocha varians (Lepidoptera: Bombycidae) in Pakistan
}

Muhammad Ramzan, Unsar Naeem-Ullah*, Naeem Iqbal, Zartasha Rasheed, Shafia Saba, Hafsah Ghaffar and Shafqat Saeed

Institute of Plant Protection, MNS-University of Agriculture Multan, Punjab-Pakistan

*Corresponding author's email:naeem1130@yahoo.com

Citation

Muhammad Ramzan, Unsar Naeem-Ullah, Naeem Iqbal, Zartasha Rasheed, Shafia Saba, Hafsah Ghaffar and Shafqat Saeed. Effect of temperature on the life cycle of Trilocha varians (Lepidoptera: Bombycidae) in Pakistan. Pure and Applied Biology. Vol. 9, Issue 1, pp436-442. http://dx.doi.org/10.19045/bspab.2020.90047

Received: 06/08/2019

Revised: 22/10/2019

Accepted: 08/11/2019

Online First: 13/11/2019

\section{Abstract}

Ficus benjamina is known as weeping fig, planted along roadsides in Pakistan to increase the aesthetic value of the country. It is native to tropical and sub-tropical regions of the world. In 2019, plants were infested by leaf eating caterpillar, identified as Trilocha varians. The larvae of the pest were caused up to $100 \%$ defoliation of $F$. benjamina. The aim of the recent study was to determine the life cycle of $T$. varians under two different environmental temperatures i.e. $26^{\circ} \mathrm{C} \pm 1.0$ controlled and uncontrolled $33^{\circ} \mathrm{C} \pm 2.0$. The recent study was obtained that there was significant difference in the time taken for eggs, larval and pupal period of $T$. varians between high and low environmental temperatures. The life cycle of the test insect, $T$. varians was increased at low temperature and reduced in high temperature. The results showed that the fecundity of female ranged from 164 to 275 and 130-190 under controlled and uncontrolled conditions respectively. T. varians has complete metamorphosis and five larval stages. The last instar transferred into dark reddish colour prior to adult formation. The longevity of females and males was $10.0 \pm 0.43$ and $5.4 \pm 0.35$ days, respectively. Pupa of the pest was obtect. Our present study results were effective for future management of $T$. varians in Pakistan.

Keywords: Bombycid moth; Climatic conditions; Life history; Ornamental plants; Pakistan

\section{Introduction}

Ficus benjamina commonly known as weeping fig is ornamental plant belong to family Moraceae. It is grown in tropical and sub-tropical regions of the world [1]. The plants can grow well in high temperature areas and it is grown to enhance the beauty of country and for landscaping purpose. These plants are planted alongside the roads to enhance the aesthetic value of many countries including Pakistan. It has medicinal value, used for the treatment of allergy and many other infections [2]. It has been reported that plant has anti-fungal and antitumor properties $[3,4]$. It is also used to remove the pollution and very toxic chemical like carbon monoxide and formaldehyde [5]. Several insect pests including mealybug and whitefly are cause damage to ficus species like Ficus benjamina and Ficus microcarpa [6-8]. Among these pests, Trilocha varians known as leaf eating caterpillar is major one 
and cause $100 \%$ defoliation [9]. T. varians is distributed in Pakistan, Philipines, Haryana, India, Tamil Nadu and Karnataka [1, 8, 1013]. Ficus religiosa, Ficus infectoria, Ficus elastica and Ficus benghalensis are also infested $[10,14,15]$. The early instars of the pest feed on leaves, roots and twigs of the plants [16]. The leaves of the plants look sieve like or appear transparent. The severe attack of pest can kill the plants and reduce the aesthetic value of plants [1].

There was still no study carried out to check the effect of climatic conditions on the life history of $T$. varians in Pakistan. Weather parameters like temperature and humidity change remain uniform throughout the year but change during rainy days in the study area. Hence, present study was carried out to determine the life cycle of $T$. varians under two environmental conditions viz., $26^{\circ} \mathrm{C}$ and $32^{\circ} \mathrm{C}$ (control and non-control respectively). The environmental conditions like temperature effect the developmental time of insect pests like $T$. varians.

The purpose of the recent study was to determine the life cycle of $T$. varians under two different environmental conditions i.e. controlled and un-controlled conditions.

\section{Materials and methods}

\section{Study area}

A study was carried out in MNS-University of Agriculture Multan $\left(30.2^{\circ} \mathrm{N}\right.$ and $\left.71.4^{\circ} \mathrm{E}\right)$ 123-meter-high above sea level from January 2019 to June 2019.

\section{Sampling site}

Immature stages such as eggs, larvae and pupae of insect were collected with the help of forceps from infested ficus plants surrounded in the University.

Rearing and life cycle of Trilocha varians

The collected live insect stages were kept into transparent plastic jars and brought to Ecology Laboratory for rearing purpose. For rearing purpose, 10 plastic containers of $2 \mathrm{~L}$ were purchased from nearby market and 10 larvae were placed in each container with natural diet, leaves of $F$. benjamina. Other stages such as pupae and eggs of pest were kept into separate plastic containers. Larvae were fed with ficus plants leaves until they reached at pupal stage. After adult emergence, a pair of moths was placed into jar for collection of eggs and mating purposes. After mating eggs, leaves were examined for eggs. After eggs lying, eggs were placed into separate containers for larvae collection. Pest was reared under two different temperature i.e. controlled $\left(26^{\circ} \mathrm{C} \pm\right.$ 1.0) and uncontrolled $\left(33^{\circ} \mathrm{C} \pm 2.0\right)$. When the eggs hatched out, larvae were released placed into containers and $F$. benjamina leaves were placed. On daily basis new leaves were provided for food and data regarding to eggs, larvae, pupa and adults recorded. Data was removed, if any stages like larvae or adults died during the study. Total of 15 and 9 specimens under controlled and uncontrolled condition respectively were successfully reared.

\section{Statistical analysis}

Data recorded regarding to developmental period of $T$. varians between controlled and uncontrolled conditions were analyzed by using Mann-Whitney test.

\section{Results and discussion}

\section{Life cycle of $T$. varians reared at $26^{\circ} \mathrm{C}$ and} $33^{0} \mathrm{C}$ temperatures

$T$. varians was passes through different stages like eggs, larval stages $\left(1^{\mathrm{st}}, 2^{\text {nd }}, 3^{\text {rd }}\right.$ and $\left.4^{\text {th }}\right)$, pupae and adults. All these stages were studied in the current experiment.

\section{Egg}

During the study, it was observed that $215 \pm$ 32.87 eggs deposited by adult female in rows on the walls of containers while dorsal surface of the leaves in field conditions. The colour of eggs was change during the developmental time. Newly laid eggs were light yellow. Before hatching, colour of eggs were change from yellow to black. Shape of eggs was round flat, rounded at base and yellow in colour. The eggs were hatch within 
six days (Mean \pm SE, $6.14 \pm 0.47$ ) and become larvae under controlled condition (Fig. 1). In the present study, eggs hatchability was recorded $95.50 \%$. Under uncontrolled conditions $\left(33^{\circ} \mathrm{C} \pm 2.0\right)$, eggs hatchability took less time (Mean \pm SE, 5.00 \pm 0.76 ) for hatching than the controlled temperature.

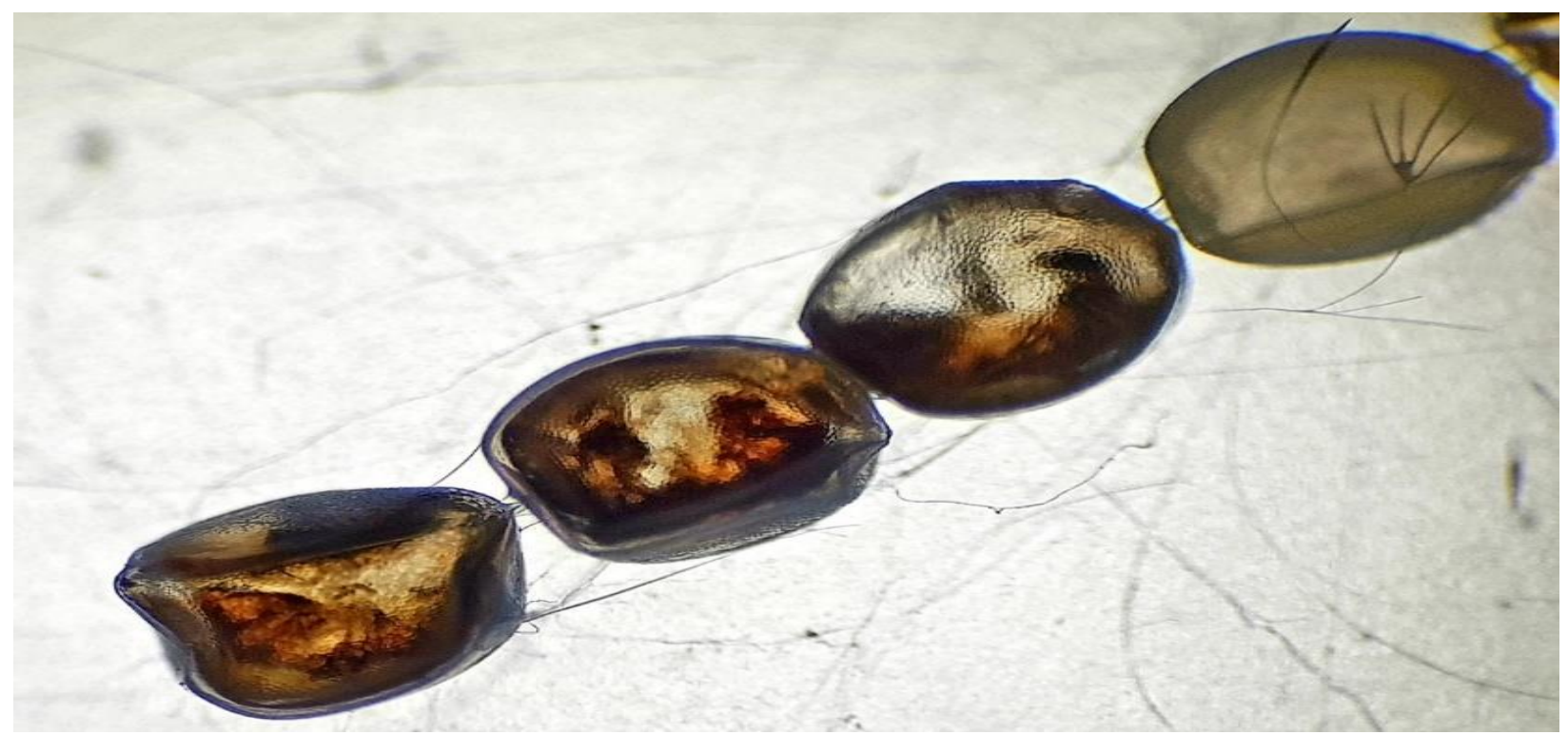

Figure 1. Egg mass of $T$. varians on $F$. benjamina leaf

The significant differences in the time taken between the two temperatures, controlled and uncontrolled conditions for eggs to hatch were $(\mathrm{N}=36, \mathrm{U}=70.00, \mathrm{p}=0.006, \mathrm{r}=0.50)$, larvae period $(\mathrm{U}=14, \mathrm{~N}=36, \mathrm{p}<0.003, \mathrm{r}=$ $0.70)$ and pupation period $(\mathrm{N}=36, \mathrm{U}=62, \mathrm{p}$ $<0.05, \mathrm{r}=0.55)$.

\section{Larva}

Body of larvae was cylindrical with five and three pairs of abdominal and thoracic legs respectively. There was a caudal horn on each larva with length of $0.50 \mathrm{~mm}$. The dorsal and lateral sides of first instar larva were white and dark green respectively. The head of $T$. varians was black. Caudal horn on second instar larva was twice long than first instar larva. White powder was present on the whole body of second instar larva. Second instar larva was less moveable than the first instar. The length of caudal horn was longer in third and fourth while reduced in fifth instars. Newly emerged larvae were brown and after 24 hours change into greyish white till last instars. Last instars were resembled with the branches of ficus plants and difficult to find them.

There were $5^{\text {th }}$ larval stages and duration of each stages $1^{\text {st }}, 2^{\text {nd }}, 3^{\text {rd }}, 4^{\text {th }}$ and $5^{\text {th }}$ of $T$. varians, last for $2.50 \pm 0.14,3.27 \pm 0.28,4.10$ $\pm 0.12,4.95 \pm 0.15$ and $6.99 \pm 0.25$ days respectively. Before changing into pupae, larval stages were lasted about 19.5 days (Mean \pm SE, $17.70 \pm$ 2.50). Under uncontrolled conditions $\left(33^{\circ} \mathrm{C} \pm 2.0\right)$, larval stage was lasted for 11 days (Mean \pm SE, 8.94 \pm 2.99 ) before changed into pupa (Fig. 2). 


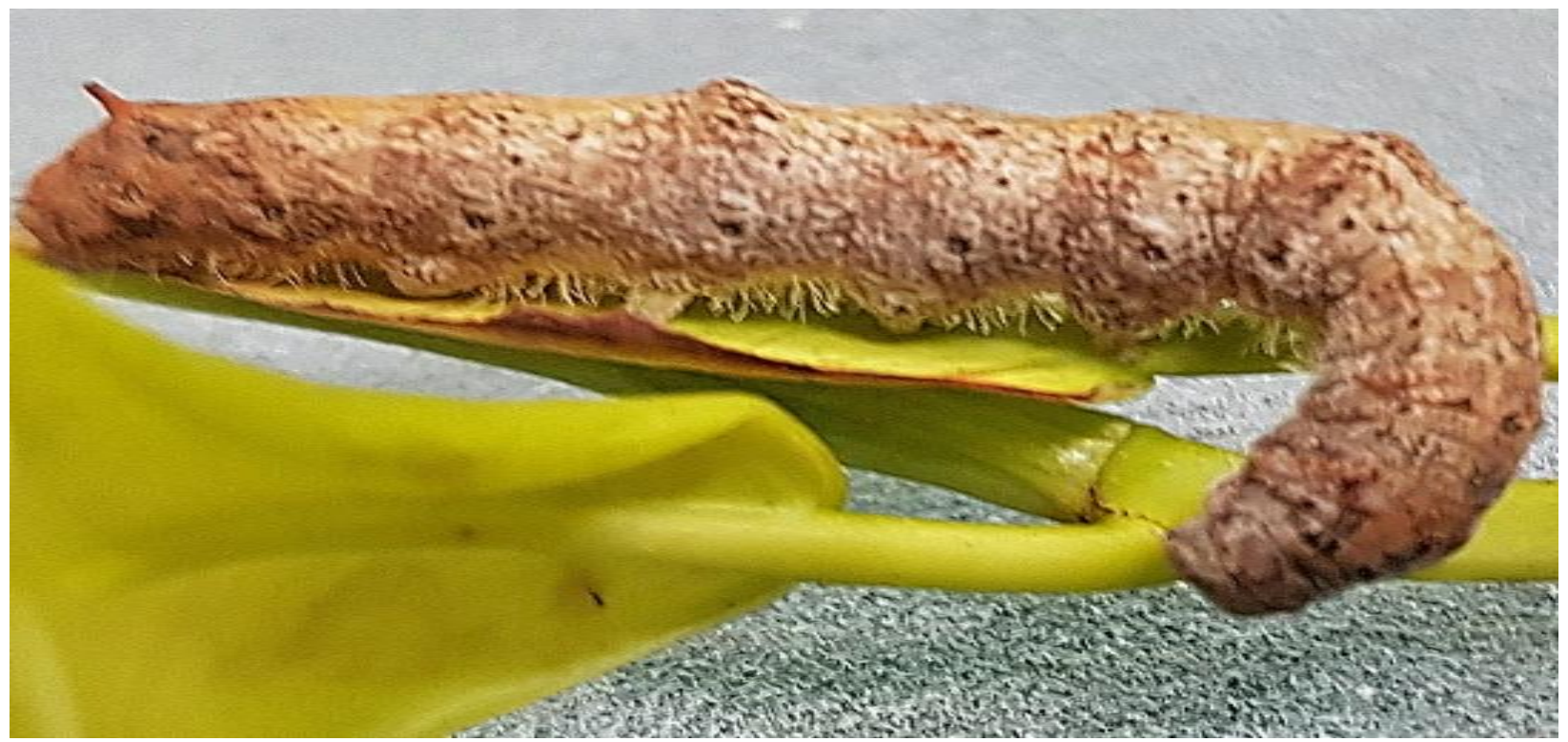

Figure 2. $T$. varians larva feeding on $F$. benjamina leaf

\section{Pupa}

Mature larva was covered itself into silken thread with boat shaped cocoon. During the whole study, colour of cocoon was change from white, bright yellow, light yellow and pinkish. Pupa of T. varians was obtect. Prior to emerging in adults, pupae took about five to six days (Mean $\pm \mathrm{SE}, 6.70 \pm 0.60$ ). The period of life cycle become shorter due to high temperature under controlled conditions. The pupal period took four and a half days (mean $\pm \mathrm{SE}, 3.00 \pm 1.93$ ) prior changed to adult (Fig.3).

Figure 3. $T$. varians pupa in silk cocoon 


\section{Adult}

In the recent study, it was observed that male was short lived as compared to female. Body parts such as head, thorax and abdomen of $T$. varians were dark reddish brown in colour. Mean longevity of both male and female was $6.6 \pm 0.01$. and $12.00 \pm 0.10$ days respectively. The outer margins of forewings and hind wings of adult were pale reddish brown and greyish reddish brown in colour respectively (Fig. 4).

There was no significant different in developmental period of both male and female under both conditions (Controlled:
Male; $27.80 \pm 3.12$ days; female; $29.09 \pm$ 1.54 days; $\mathrm{N}=22, \mathrm{U}=29.5, \mathrm{p}=0.18, \mathrm{r}=$ 0.32; and Uncontrolled; Male; 23.00 0.99 days; female; $22.67 \pm 2.25$ days; $\mathrm{N}=18, \mathrm{U}=$ $26.5, p=0.94, r=0.05)$. The recent study was conducted to determine the effect of temperature i.e. controlled and uncontrolled on life cycle of $T$. varians in Pakistan. During the study, it was observed that at high temperature developmental period was shorter from egg to adult while longer under low temperature. Our findings were similar to the earlier studies [9].

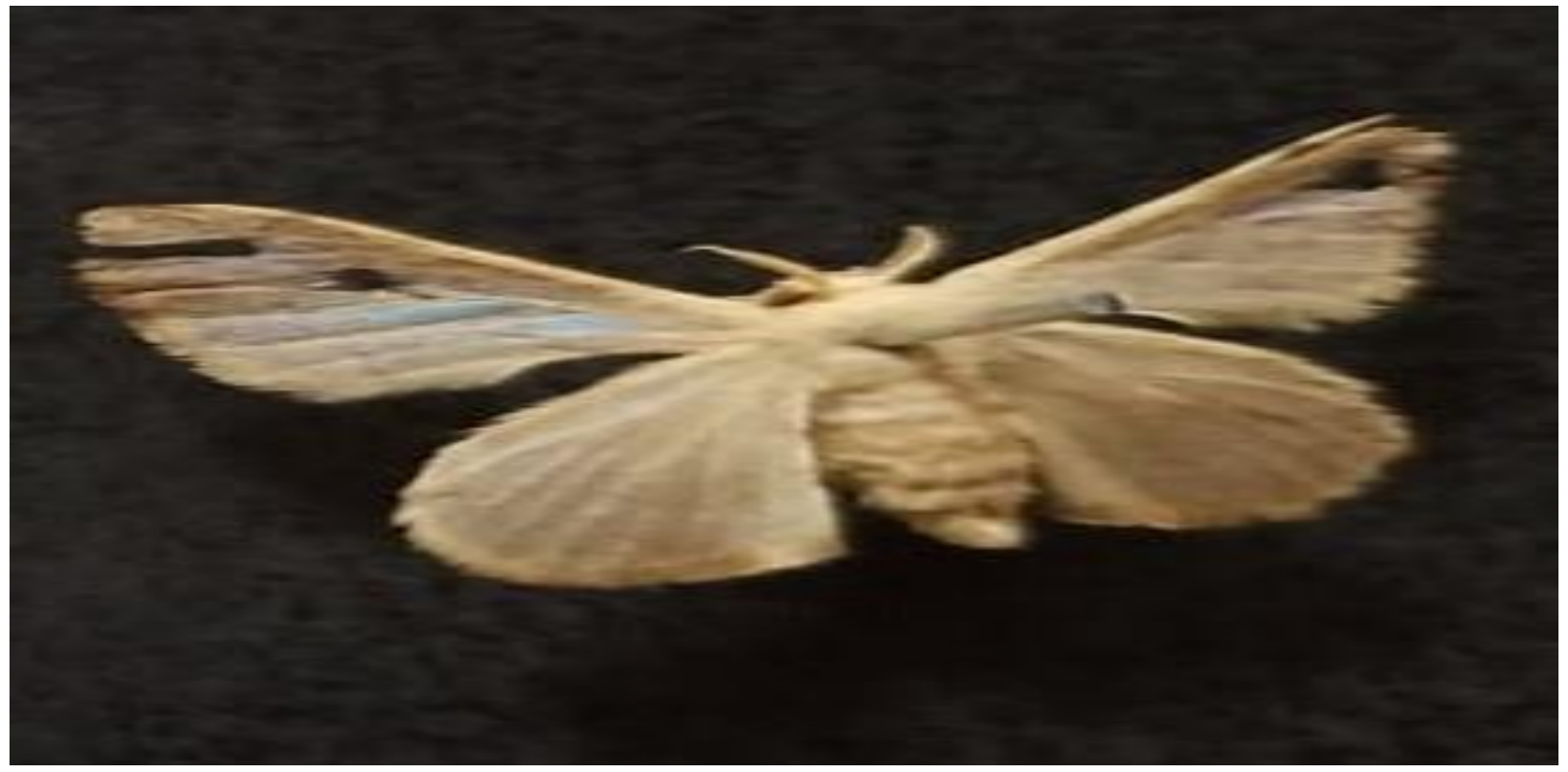

Figure 4. Adult of T. varians

At an earlier stage, low temperature affected the $T$. varians development. Similar findings had been observed by other researchers [14, $17,18]$. In recent study, it was observed that developmental period also affected through monsoon season. The similar results about effect of monsoon season on developmental period of pest had been performed by other researchers [9]. During monsoon season (October-March), developmental period of pest was longer while shorter in dry season (April-September). The population of $T$. varians was at peak point in October to March and infestation rate also maximum during these months. In these months (October-March), developmental period was longer, larvae took more time to change into pupae, fed maximum plants and cause $100 \%$ defoliation.

There was a long caudal horn on $8^{\text {th }}$ abdominal segment of early instars of $T$. varians. Same disruption had been described by other workers [3]. Pupation was taken placed into silken cocoon. Similar 
observations had been observed by earlier studies [12]. The developmental periods from eggs to larva, larva to pupa and pupa to adults under uncontrolled as well as controlled conditions were similar to earlier studies [9, 16, 19].

\section{Conclusion}

The environmental conditions such as temperature was affected the life period of insect pests especially $T$. varians. The developmental time of pest was changed with variations in climate. This was the first study regarding life cycle of $T$. varians under two different temperatures in Pakistan. This study will be proved to be helpful for future pest control in Pakistan.

\section{Authors' contributions}

Conceived and designed the experiments: UN Ullah, Performed the experiments: M Ramzan, Analyzed the data: N Iqbal \& Z Rasheed, Contributed materials/ analysis/ tools: S Saba, H Ghaffar \& S Saeed, Wrote the paper: M Ramzan.

\section{Acknowledgment}

We thanks to MNS- University of Agriculture Multan for providing facilities and equipments used to perform the present research work. Authors are highly thankful to DR. M. Sankar Manickanm, Scientist (Agri. Entomology) in India for critical review of recent study.

\section{References}

1. Zolotuhin VV, Witt TJ (2009). The Bombycidae of Vietnam. Entomofauna 16:231-272.

2. Sirisha N, Sreenivasulu M, Sangeeta K \& Chetty CM (2010). Antioxidant Properties of Ficus Species - A Review. J. Pharm Tech Res 2: 2174-2182.

3. Lansky EP, Helena MP, Alison DP \& Robert AN (2008). Ficus spp. (fig): Ethnobotany and potential as anticancer and anti-inflammatory agents, $J$. Ethnopharmacol 119: 195-213.

4. Mousa O, Vuorela P, Kiviranta I, Abdel Wahab S, Hiltunen R \& Vuorela $\mathrm{H}$
(1994). Bioactivity of certain Egyptian Ficus species. J. Ethnopharmacol 41: 71-76.

5. Kim KJ, Kil MJ, Song JS, Yoo EH, Son K \& Kays SJ (2008). Efficiency of Volatile Formaldehyde Removal by Indoor Plants: Contribution of Aerial Plant Parts versus the Root Zone. J Am Soc Hortic Sci 133: 521-526.

6. Avery PB, Mannion CM, Powell CA, McKenzie CL \& Osborne LS (2011). Natural Enemies Managing the Invasion of the Fig Whitefly, Singhiella simplex (Hemiptera: Aleyrodidae), Infesting a Ficus benjamina Hedge. Fla. Entomol 94: 696-698.

7. Ou HY, Ruan L, Luo M, Cen YJ, He YR \& Tian MY (2006) Parasitizing capacity of several trichogrammatid species on Ocinara varians. Chin Bull. Ent 43:669672.

8. Udayagiri S (1988). Life history and new records of natural enemies of Trilocha varians (Walker) (Lepidoptera: Bombycidae). Ann Entomol Soc Am 6:16.

9. Basari N, Mustafa NS, Yusrihan NEN, Yean CW \& Ibrahim Z (2019). The Effect of Temperature on the Development of Trilocha varians (Lepidoptera: Bombycidae) and Control of the Ficus Plant Pest. Trop Life Sci Res 30: 23.

10. Kedar SC, Kumaranag KM \& Saini RK (2014). First report of Trilocha (=Ocinara) varians and its natural enemies on Ficus spp. from Haryana, India. J Entomol Zool Stud 2: 268-270.

11. Kishida Y (2002). Trilocha varians (Walker) (Bombycidae) from Ishigaki Island, the Ryukyus. Japan Heterocerist's J 219370.

12. Rajavel DS \& Shanthi M (2007). Note on the first occurrence of Trilocha (=Ocinara) varians walker (Bombycidae: Lepidoptera) as a pest of 
pipal tree (Ficus religiosa) in Madurai, Tamil Nadu. J. Indian For133:17061708.

13. Singh A \& Brar JS (2016). First record of Trilocha varians (Family: Bombycidae) a pest of Ficus benjamina (L.) and its biology in Talwandi Sabo, Dist Bathia, Punjab. Inter J Sci Nat 7: 711-713.

14. Daimon T, Yago M, Hsu YF, Fujii T, Nakajima Y, Kokusho R \& Shimada T (2012). Molecular phylogeny, laboratory rearing, and karyotype of the bombycid moth, Trilocha varians. J Insect Sci 12: 49.

15. Navasero MV, Navasero MM, Roxas MC \& Calumpang SF (2013). Occurrence of the moraceae feeding bombycid, Trilocha varians (Walker) (Bombycid, Lepidoptera) as pest of jackfruit and some ornamental species of Ficus in the Philippines. J ASAS 19: 4148.

16. Navasero MM \& Navasero MV (2014). Biology of Trilocha varians (Walker) (Lepidoptera: Bombycidae) on Ficus benjamina L. J Philpp Entl 28: 43-56.

17. Lu B, Tang Z, Bellis G, Li Y, Peng Z, Jin Q \& Wen H (2016). Life table analysis under constant temperature for Opisina arenosella (Lepidoptera: Xyloryctidae), an invasive moth of palm plants. Aust Entomol 55: 2334-339.

18. Sibly ARM, Winokur L \& Smith RH (2016). Interpopulation variation in phenotypic plasticity in the speckled wood butterfly. J Oikos 78: 323-330.

19. Jia L \& Jinxin L (1997). Studies on the bionomics of Ocinara varians Walker. Entomol J East Chinn 40:31-34. 